\title{
Relationship between plasma plasminogen activator inhibitor-1 activity and VLDL triglyceride concentration, insulin levels and insulin sensitivity: studies in randomly selected normo- and hypertriglyceridaemic men
}

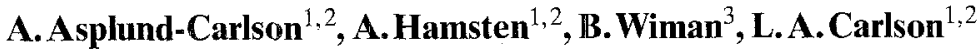 \\ ${ }^{1}$ King Gustaf V Research Institute, Karolinska Institute, Karolinska Hospital, Stockholm, Sweden \\ ${ }^{2}$ Department of Internal Medicine, Karolinska Institute, Karolinska Hospital, Stockholm, Sweden \\ ${ }^{3}$ Department of Clinical Chemistry, Karolinska Institute, Karolinska Hospital, Stockholm, Sweden
}

\begin{abstract}
Summary. Impaired fibrinolytic function secondary to elevated plasma plasminogen activator inhibitor-1 activity, hypertriglyceridaemia and hyperinsulinaemia are frequent findings in patients with coronary heart disease. It has been debated whether VLDL or insulin is the major regulator of plasma plasminogen activator inhibitor-1 activity. This study examines the relationships between plasma plasminogen activator inhibitor- 1 activity and VLDL triglyceride concentration, fasting and post-oral glucose load insulin levels and insulin sensitivity, as estimated by the minimal model method. Subjects studied were randomly selected hypertriglyceridaemic $(n=65)$ and age-matched normotriglyceridaemic $(n=61)$ men, aged 40-50 years, recruited in a population survey. Plasma plasminogen activator inhibitor-1 activity was higher in the hypertriglyceridaemic than in the normotriglyceridaemic group $(21 \pm 14 \mathrm{vs} 10 \pm 8 \mathrm{mU} / \mathrm{l} ; p<0.01)$. The hypertriglyceridaemic group had higher serum insulin, basal as well as $2 \mathrm{~h}$ after intake of the oral glucose load, and a lower insulin sensitivity index. In univariate analysis, plasma plasminogen activator inhibitor-1 activity correlated positively
\end{abstract}

with VLDL triglycerides in both the hyper- and normotriglyceridaemic groups ( $r=0.43 r=0.60$, respectively) and negatively with the insulin sensitivity index $(r=-0.35 r=-0.44$, respectively). In multivariate analysis, VLDL triglyceride levels were found to be independently related to plasma plasminogen activator inhibitor-1 activity in both groups, whereas insulin sensitivity/serum insulin levels were not. An unexpected finding was that the serum activity of the enzyme gamma glutamyl transpeptidase appeared to influence the relationships for plasma plasminogen activator inhibitor- 1 in the hypertriglyceridaemic group. In conclusion, this population-based study indicates that VLDL triglyceride concentration is one of the major determinants of plasma plasminogen activator inhibitor- 1 activity in both normotriglyceridaemic and hypertriglyceridaemic men.

Key words: Plasminogen activator inhibitor- 1 , hypertriglyceridaemia, VLDL, insulin, insulin sensitivity, minimal model, gamma glutamyl transpeptidase.
The relationships between hypertriglyceridaemia and coronary heart disease (CHD) have been much discussed concerning both non-diabetic subjects as well as non-insulin-dependent diabetic patients [1-3]. The clustering of hypertriglyceridaemia with low concentrations of HDL cholesterol, hypertension, central obesity and insulin resistance, termed "syndrome X" by Reaven [4], and the association of hyperinsulinaemia with raised triglyceride and LDL cholesterol and low HDL cholesterol levels [5] have attracted considerable interest in this context. Impaired fibrinolytic function secondary to elevated plasma plasminogen activator inhibitor-1 (PAI-1) activity has recently been shown to be associated with hypertriglyceridaemia [6] as well as hyperinsulinaemia $[7,8]$ and is a frequent finding in men who survive myocardial infarction $[9,10]$.

The introduction of sensitive and specific methods to determine the individual components of the fibrinolytic enzyme system has resulted in an abundance of cross-sectional studies of these elements in patients with angina pectoris or previous myocardial infarction, as reviewed by Wiman and Hamsten [11]. These reports have consistently shown a decreased fibrinolytic activity in patients compared with control subjects. The major mechanism for the fibrinolytic impairment seen in patients with CHD is, without doubt, PAI-1 activity elevation in plasma. Data from our group have indicated that elevated plasma levels of PAI-1 may be of pathogenic importance in myocardial infarction, especially in young patients with hypertriglyceridaemia $[6,12]$. The positive and fairly strong relationship between serum triglycerides and PAI1 levels in plasma $[6,13,14]$ is of particular interest, since it suggests that hypertriglyceridaemia may be linked with a predisposition to thrombosis through a coexisting increase in PAI-1 concentration. It has been proposed that 
Table 1. Serum triglyceride (TG), very low density lipoprotein (VLDL)-TG, gamma-glutamyltranspeptidase ( $\gamma$-GT), age, anthropometric data and life style characteristics of normo-(NTG) and hypertriglyceridaemic (HTG) subjects

\begin{tabular}{|c|c|c|c|c|c|c|}
\hline & $\begin{array}{l}\text { NTG } \\
n=61\end{array}$ & $\begin{array}{l}\text { HTG, } \\
\text { all } \\
n=65\end{array}$ & $p^{a, b}$ & $\begin{array}{l}\text { HTG, } \\
\text { normal } \gamma-\mathrm{GT}^{\mathrm{c}} \\
n=35\end{array}$ & $\begin{array}{l}\text { HTG, } \\
\text { elevated } \gamma-\text { GT }^{c} \\
n=29\end{array}$ & $p^{\text {a }}$ \\
\hline $\begin{array}{l}\text { TG } \\
(\mathrm{mmol} / \mathrm{l})\end{array}$ & $1.28 \pm 0.53$ & $3.81 \pm 1.65$ & $<0.001$ & $3.91 \pm 1.92$ & $3.64 \pm 1.27$ & NS \\
\hline $\begin{array}{l}\text { VLDL-TG } \\
(\mathrm{mmol} / \mathrm{l})\end{array}$ & $0.82 \pm 0.49$ & $3.00 \pm 1.48$ & $<0.001$ & $3.12 \pm 1.72$ & $2.85 \pm 1.17$ & NS \\
\hline $\begin{array}{l}\mathrm{BMI} \\
\left(\mathrm{kg} / \mathrm{m}^{2}\right)\end{array}$ & $24.7 \pm 2.7$ & $27.8 \pm 3.8$ & $<0.001$ & $27.8 \pm 3.9$ & $27.8 \pm 3.7$ & NS \\
\hline Waist to hip ratio & $0.95 \pm 0.05$ & $1.00 \pm 0.06$ & $<0.001$ & $0.99 \pm 0.06$ & $1.01 \pm 0.05$ & NS \\
\hline $\begin{array}{l}\text { Current smokers } \\
\mathrm{n}(\%)\end{array}$ & $16(26)$ & $28(43)$ & $<0.05$ & $14(40)$ & $13(45)$ & NS \\
\hline $\begin{array}{l}\text { Alcohol } \\
\mathrm{g}(\%)\end{array}$ & $16 \pm 13(4 \pm 3)$ & $27 \pm 24(6 \pm 5)$ & $<0.01$ & $19 \pm 15(4 \pm 4)$ & $36 \pm 28(9 \pm 9)$ & $<0.01$ \\
\hline $\begin{array}{l}\gamma-\mathrm{GT} \\
(\mu \mathrm{kat} / \mathrm{l})\end{array}$ & $0.60 \pm 0.41$ & $1.22 \pm 1.00^{\mathrm{f}}$ & $<0.001$ & $0.63 \pm 0.17$ & $1.93 \pm 1.14$ & $<0.001$ \\
\hline
\end{tabular}

Values are shown as mean $\pm \mathrm{SD}$ or $\mathrm{n}(\%)$.

a Student's unpaired two-sided $t$-test were used for comparison.

${ }^{\mathrm{b}}$ Chi-square analysis, with Yates correction was used for comparison of current smokers and physical activity.

${ }^{c}$ Normal $\gamma$-GT $<1.00 \mu \mathrm{kat} /$; Elevated $\gamma$-GT $\geq 1.00 \mu \mathrm{kat} / \mathrm{l}$.

${ }^{\mathrm{d}}$ With a sedentary leisure time.

${ }^{e}$ Daily amount alcohol consumed; gram per day and percent of daily energy intake.

${ }^{\mathrm{i}} n=64$

plasma insulin is the major physiological regulator of PAI-1 activity in plasma and thereby of fibrinolytic activity $[7,15,16]$. The mechanism may be either direct or indirect via the influence of insulin on plasma triglyceride concentration. A significant inverse correlation has also been noted between insulin sensitivity, measured with the euglycaemic clamp technique and plasma PAI-1 activity [17].

Against this background we investigated the relationships between plasma PAI-1 activity and serum VLDL triglyceride concentration, serum insulin and insulin sensitivity in randomly selected hypertriglyceridaemic males and age-matched normolipidaemic control men participating in the same screening programme.

\section{Subjects and methods}

\section{Subjects and study protocol}

Hypertriglyceridaemia was defined as the top $5 \%$ of the fasting serum triglyceride distribution of 1564 randomly selected and screened men, $40-50$ years of age, living in the northern part of the Stockholm area, Sweden. Based upon previous experience from this laboratory the 95th percentile of this distribution was initially set at $3.1 \mathrm{mmol} / \mathrm{l}$. The final $95 \mathrm{th}$ percentile for the serum triglyceride concentration was 3.05 .

Eighty-one men of the 1,564 screened, were defined as hypertriglyceridaemic (HTG). For each HTG man, not excluded by the criteria mentioned below, an age-matched normotriglyceridaemic
(NTG) control subject with a serum triglyceride value below the 95th percentile of the background population was selected at random.

Both the HTG and NTG men were contacted, followed by further investigations at the Karolinska Hospital within 3 weeks. Acceptance rate was $100 \%$ for the HTG population and $85 \%$ for the NTG subjects. Of the HTG and NTG men $50 \%$ had been screened during the same week, for the remainder the difference was not more than 3 weeks.

Of the randomly selected HTG men 16 were excluded from further investigations due to medical conditions or treatments that might influence the metabolic studies. Sixty-five HTG men completed the programme. Of the 65 matched control subjects four were also excluded for conditions affecting the studies. Thus, 61 NTG men completed the investigation.

The HTG group included eight men with a diagnosis of hypertension of whom five were drug treated (ACE-inhibitor in one case, thiazide in one case, beta-blocker in three cases) and two patients with untreated CHD (angina pectoris). The NTG group included one patient with a diagnosis of mild, untreated hypertension.

The protocol was as follows: two men, one HTG and one NTG, were examined each week (except holidays) over a 2-year period, spring 1990-spring 1992. Starting on a Monday the medical history was taken and the clinical examination performed by one of us (AAC). The same dietician took a dietary history for each patient. On the following day after a 12-h overnight fast, blood sampling for determination of serum lipoproteins and PAI- 1 activity was performed between 08.00 and 09.00 hours. On day 5 at 09.00 hours, after a 12-h overnight fast, a frequently sampled intravenous glucose tolerance test (FSIGT) [18] was performed. Finally, day 10, at 09.00 hours, after a 12 -h overnight fast, an oral glucose tolerance test (OGTT) was performed. All men had been counselled by the dietician to consume a weight maintaining diet containing at least $300 \mathrm{~g}$ of carbohydrate per day throughout the study period. 


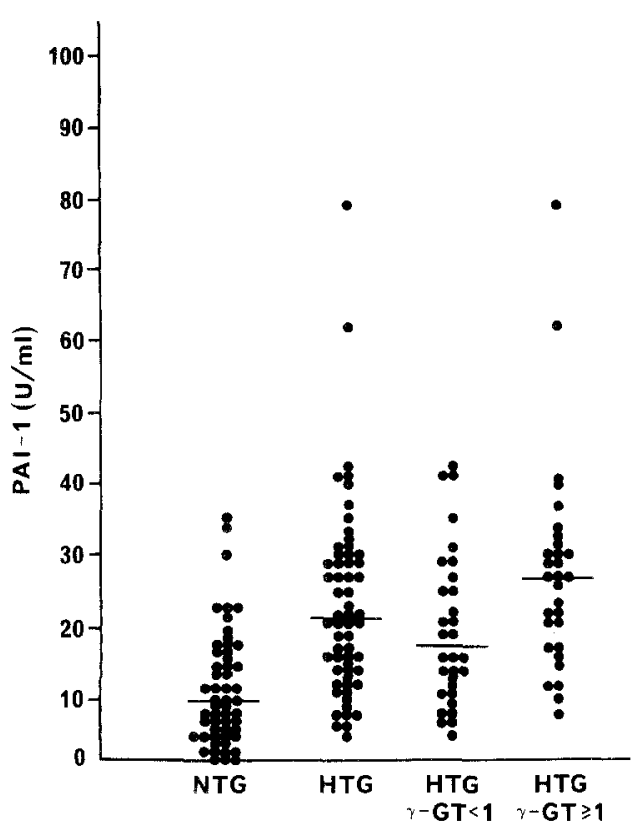

Fig. 1. Distributions, mean $\pm \mathrm{SD}$, of plasma plasminogen activator inhibitor (PAI-1) activities in the normo-(NTG) and hypertriglyceridaemic (HTG) groups $(10 \pm 8$ vs $21 \pm 14 ; p<0.01)$, respectively in HTG subjects with normal vs elevated gamma glutamyl transpeptidase $(\gamma$-GT $)$ activities $(17 \pm 12$ vs $26 \pm 15 ; p<0.05)$

The study was approved by the ethical committee at the Karolinska Institute, and all participants had given informed consent.

\section{Alcohol intake}

Daily dietary intake including alcohol, was evaluated, by a combination of dietary history and 5-day registration of menu [19]. The history was taken without knowledge of whether or not the patient was hypertriglyceridaemic.

\section{Anthropometry}

Weight was recorded with subjects in trousers but without shoes and jacket. Height was measured without shoes. Body mass index (BMI) was calculated as the ratio between body weight in kilograms and height in squared meters. Waist and hip were measured with a steel tape to the nearest half centimeter with subjects in the lying position; waist from a point half the distance between the lowest rib cage, and spina iliaca, in the mid-axillary line, hip at a point corresponding to the hip joints. Waist to hip ratio (WH) was then calculated.

\section{Laboratory methods}

Serum lipoproteins were determined by a combination of ultra-centrifugation and precipitation of apolipoprotein B-containing lipoproteins followed by lipid analysis as described [20]. Whole blood glucose was determined enzymatically (Gluco-quant Glucose; Boehringer Mannheim Diagnostica, Mannheim, FRG). Serum insulin was measured by an RIA method (Pharmacia Insulin RIA, Uppsala, Sweden). PAI-1 was assayed as activity in plasma [21] utilizing a commercially available kit (Biopool, Umeå, Sweden).

\section{Oral glucose tolerance test}

A standard dose of $75 \mathrm{~g}$ of glucose in $200 \mathrm{ml}$ of water was ingested and venous blood samples drawn at 0 and $120 \mathrm{~min}$ for determination of whole blood glucose and serum insulin. Glucose intolerance was defined according to WHO criteria [22].

\section{Frequently sampled intravenous glucose tolerance test insulin sensitivity}

The FSIGT was modified by insulin [23]. A standard dose of $25 \mathrm{~g}$ of glucose (dextrose, $25 \mathrm{~g} / 100 \mathrm{ml}$ ) was given as an i. v. injection over the first $0-2 \mathrm{~min}$ of the test. At $20 \mathrm{~min}$, an $\mathrm{i}$. v. injection of regular insulin (0.02 IU/kg body weight, Actrapid Human; Novo Nordisk, Bagsværd, Denmark) was given.

The MINMOD computer program [24] (purchased from the University of Southern California, Department of Physiology and Biophysics, Los Angeles, Calif., USA, copyright RN Bergman) was used to calculate insulin sensitivity from the results of the FSIGT.

\section{Statistical analysis}

Calculations were run by the $\mathrm{dB}$ Stats computer program as well as SPSS/PC + Advanced Statistics Program (both from SPSS Inc, Chicago, Ill., USA). Student's unpaired two-tailed $t$-test was used for comparison of group means. Where variances were unequal, separate variance estimates were used. Triglycerides were logarithmically transformed in the uni- and multivariate analysis, because of the skewed serum triglyceride distribution.

Pearson linear correlation coefficients were calculated, and in case of outliers Spearman rank coefficients were also determined. In the multiple, stepwise, linear regression model, the variable with the highest partial correlation coefficient was entered at each step until no variable remained $(p<0.05)$ and removed $(p>0.10)$ in order of statistical significance.

Due to the previous observation that HTG men with high $\gamma$-GT values in their blood lacked some of the usual metabolic correlates existing for VLDL (Asplund-Carlson A, unpublished observation) the HTG population was divided into low and high $\gamma$-GT subgroups.

\section{Results}

\section{Basic characteristics of the subjects (Table 1)}

The HTG group had a significantly higher BMI as well as a higher WH ratio compared to the NTG group. A higher proportion of smokers and of men with a sedentary life style during their leisure time was found in the HTG compared to the NTG group. The HTG subjects, as a group, reported a significantly higher alcohol intake than the NTG subjects. However, the higher alcohol intake of the HTG group, was confined to the sub-group of HTG men with elevated $\gamma$-GT levels $(\geq 1.00 \mu \mathrm{kat} / 1)$.

With the exception of alcohol intake, there were no differences in basic characteristics of the two sub-groups of HTG men, with normal and elevated $\gamma$-GT levels, respectively. Notably mean serum triglyceride levels were comparable in the two sub-groups, as were HDL cholesterol levels (0.98 vs $1.05 \mathrm{mmol} / \mathrm{l}$; NS). 
Table 2. Glucose/insulin response during the oral glucose tolerance test and insulin sensitivity index $\left(S_{I}\right)$ in normo-(NTG) and hypertriglyceridaemic (HTG) subjects.

\begin{tabular}{|c|c|c|c|c|c|c|}
\hline & $\begin{array}{l}\text { NTG } \\
n=59\end{array}$ & $\begin{array}{l}\text { HTG, } \\
\text { all } \\
n=63\end{array}$ & $p^{a}$ & $\begin{array}{l}\text { HTG, } \\
\text { normal } \gamma \text {-GT } \\
n=34\end{array}$ & $\begin{array}{l}\text { HTG, } \\
\text { elevated } \gamma \text {-GT } \\
n=28\end{array}$ & $p^{a}$ \\
\hline $\begin{array}{l}\text { Glucose } \\
0 \mathrm{~min} \\
(\mathrm{mmol} / \mathrm{l})\end{array}$ & $4.71 \pm 0.37$ & $5.09 \pm 0.50$ & $<0.001$ & $4.92 \pm 0.41$ & $5.28 \pm 0.55$ & $<0.01$ \\
\hline $\begin{array}{l}\text { Glucose } \\
120 \mathrm{~min} \\
(\mathrm{mmol} / \mathrm{l})\end{array}$ & $5.27 \pm 1.31$ & $6.34 \pm 1.84$ & $<0.001$ & $6.44 \pm 1.78$ & $6.22 \pm 1.93$ & NS \\
\hline $\begin{array}{l}\text { Insulin } \\
0 \text { min } \\
(\mathrm{mU} / 1)\end{array}$ & $6.55 \pm 2.81$ & $12.46 \pm 12.14$ & $<0.001$ & $11.04 \pm 8.89$ & $14.43 \pm 15.28$ & NS \\
\hline $\begin{array}{l}\text { Insulin } \\
120 \mathrm{~min} \\
(\mathrm{mU} / 1)\end{array}$ & $36.30 \pm 28.56$ & $67.83 \pm 48.50$ & $<0.001$ & $69.45 \pm 54.95$ & $67.24 \pm 40.64$ & NS \\
\hline
\end{tabular}

Values are shown as mean \pm SD.

${ }^{a}$ Students unpaired two-tailed $t$-test was used for comparison.

${ }^{\mathrm{b}} n=58 ;{ }^{\mathrm{c}} n=61 . \gamma$-GT, gammaglutamyltranspeptidase

\section{Plasma-PAI-1 activity (Fig. 1)}

The HTG group had a significantly higher mean plasma PAI-1 activity level compared to the NTG group. The inter-individual variation of plasma PAI-1 activity levels was greater in the HTG group. Comparing the two HTG sub-groups with normal and elevated $\gamma$-GT levels, respectively, the sub-group with elevated $\gamma$-GT levels had a significantly higher mean level of plasma PAI-1 activity than the sub-group with normal $\gamma$-GT levels. This was the case even if the two subjects with extremely high plasma PAI-1 activity were excluded from the analysis $(26 \pm 15$ vs $17 \pm 12 ; p<0.05$ ). Considering the two HTG sub-groups with normal or elevated $\gamma$-GT levels separately, each of them had significantly higher mean PAI-1 levels compared to the NTG group, as assessed by analysis of variance with the Bonferroni test.

\section{OGTT (Table 2)}

The HTG group had significantly higher mean levels of glucose and insulin in blood/serum, fasting as well as postload, compared to the NTG group. The HTG group included a strikingly higher proportion of glucose intolerant men defined as a value for whole blood glucose above $6.7 \mathrm{mmol} / \mathrm{l}$ at 2 -h post-load than did the NTG group ( $38 \%$ vs $8 \% ; p<0.001)$. In neither group did any of the subjects have a 2 -h glucose level greater than $11.0 \mathrm{mmol} / \mathrm{l}$.

\section{Insulin sensitivity (Table 2)}

A significantly lower mean $\mathrm{S}_{\mathrm{I}}$-index was found in the HTG group, compared to the NTG group. No difference in insulin sensitivity between the two HTG sub-groups with normal, and elevated $\gamma$-GT levels, respectively was seen. The $\mathrm{S}_{\mathrm{I}}$-index was correlated to fasting blood glucose values in both the NTG and HTG groups, $r=-0.54$ $(p<0.001)$ and $r=-0.33(p<0.01)$, respectively. Corresponding values for glucose at $120 \mathrm{~min}$ were $r=-0.60$ and $r=-0.57$, respectively.

\section{Relationship between anthropometric data, $\gamma-G T$ and plasma PAI-1 activity (Table 3, Fig. 2)}

BMI was significantly and positively, correlated with the PAI-1 level in the NTG group as well as in the HTG group with normal $\gamma$-GT values as was the WH ratio. The linear regression analysis (Fig.2) showed that there was no difference in slope for the regressions of PAI-1 on BMI in the two groups.

In contrast to the NTG group and the HTG sub-group with normal $\gamma$-GT levels, there was no relationship between either BMI or WH ratio and PAI-1 levels in the HTG sub-group with elevated $\gamma$-GT levels. Instead, plasma PAI1 activity level was found to be significantly and positively correlated to the serum $\gamma$-GT activity in this group while these relationships were seen in neither the NTG group nor the HTG sub-group with normal $\gamma$-GT levels.

\section{Relationship between life style parameters and PAI-1 activity (data not shown)}

Smoking did not correlate to a significant degree with plasma PAI-1 activity levels in either the NTG $(0.20 ; \mathrm{NS})$ or in the HTG $(0.18$; NS) groups. Similarly no relationships were found between PAI-1 level and reported alcohol intake (0.13; NS, 0.25 ; NS) or physical activity during leisure time $(-0.22 ; \mathrm{NS},-0.11 ; \mathrm{NS})$ in either the NTG or 
Table 3. Pearson linear correlation coefficients between anthropometric data, gamma-giutamyltranspeptidase $(\gamma-G T)$ and plasma plasminogen activator inhibitor-1 (PAI-1) activities in normo(NTG) and hypertriglyceridaemic (HTG) subjects

\begin{tabular}{lcll}
\hline & $\begin{array}{l}\text { PAI-1 } \\
\text { vs } \\
\text { BMI }\end{array}$ & $\begin{array}{l}\text { PAI-1 } \\
\text { vs } \\
\text { WH }\end{array}$ & $\begin{array}{l}\text { PAI-1 } \\
\text { vs } \\
\gamma \text {-GT }\end{array}$ \\
\hline $\begin{array}{l}\text { NTG } \\
n=61 \\
\text { HTG, } \\
\text { all } \\
n=65\end{array}$ & $0.66^{\mathrm{b}}$ & $0.40^{\mathrm{a}}$ & 0.19 \\
$\begin{array}{l}\text { HTG, } \\
\text { normal } \gamma \text {-GT } \\
n=35\end{array}$ & 0.28 & $0.39^{\mathrm{a}}$ & $0.50^{\mathrm{b}, \mathrm{d}}$ \\
$\begin{array}{l}\text { HTG, } \\
\text { elevated } \gamma \text {-GT } \\
n=29\end{array}$ & $0.48^{\mathrm{a}}$ & $0.59^{\mathrm{b}}$ & 0.26 \\
\hline
\end{tabular}

${ }^{\mathrm{a}} \mathrm{p}<0.01,{ }^{\mathrm{b}} \mathrm{p}<0.001$ significance of $\mathrm{r}$-values

c Normal $\gamma-\mathrm{GT}<1.00 \mu \mathrm{kat} / \mathrm{l}$; elevated $\gamma-\mathrm{GT} \geq 1.00 \mu \mathrm{kat} / \mathrm{l} .{ }^{\mathrm{d}} n=64$. WH, Waist to hip ratio

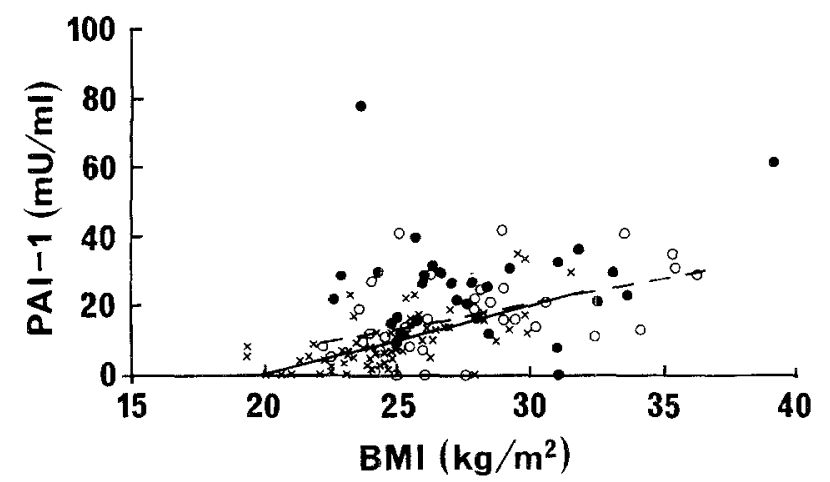

Fig. 2. Relationship between PAI-1 activity and BMI. $x-\times$ NTG men (equation $y=1.97 x-38.9$ ). $0--\circ$ HTG men with $\gamma$-GT $<1$ (equation $y=1.47 x-23.4$ ). $\bullet$ HTG men with $\gamma$-GT $\geq 1$

in the HTG group. This was the case even if the levels of $\gamma$ GT were considered.

\section{Relationship between serum lipoproteins and plasma PAI-1 activity (Table 4, Fig. 3)}

PAI-1 was significantly and positively correlated with the serum VLDL-triglyceride level in both the NTG and the HTG groups. However, the correlation coefficient for the NTG group was higher implying a higher degree of linearity for the relationship. In the two sub-groups of HTG men, with normal and elevated $\gamma$-GT levels, respectively, the correlation coefficients were comparable. In the HTG sub-group with elevated $\gamma$-GT levels, the correlation between VLDL-triglycerides and PAI-1 was significant at the $5 \%$ level. The Spearman rank correlation coefficient between these two variables in this sub-group was 0.46 $(p<0.01)$. As shown in Figure 3 the slopes for the regression lines of PAI-1 on $\log$ VLDL triglyceride concentration were quite similar in the NTG and HTG groups with normal $\gamma-G T$.
There were no significant correlations for LDL-triglycerides with plasma PAI-1 activity in either the NTG group $(-0.02 ; \mathrm{NS})$ or in the HTG group $(0.14 ; \mathrm{NS})$. Similarly, no significant relationships were found between HDL cholesterol and plasma PAI-1 activity in either NTG $(-0.23$; NS $)$ or HTG men $(0.17$; NS $)$.

\section{Relationship between OGTT, glucose/insulin responses and PAI-1 activity (Table 4)}

A striking difference regarding the relationship between fasting blood glucose and plasma PAI-1 activity was seen between NTG and HTG men, in that there was a significant correlation between fasting blood levels of glucose and plasma PAI-1 activity only in the HTG group, but none in the NTG group. Moreover, the association between fasting blood glucose and PAI-1 levels was accounted for by the HTG sub-group with normal $\gamma$-GT levels, whereas no significant correlation was seen between fasting blood glucose and PAI-1 activity in the HTG subgroup with elevated $\gamma$-GT levels. No significant correlations between post-load glucose and PAI-1 levels were seen, in any of the groups (data not shown).

Fasting serum insulin level was significantly correlated with plasma PAI-1 activity exclusively in the HTG subgroup with normal $\gamma$-GT levels. Post-load $2-h$ insulin and PAI-1 levels were significantly correlated in the NTG group and in the HTG sub-group with normal $\gamma$-GT levels, but not in the HTG sub-group with elevated $\gamma$-GT levels.

\section{Relationship between insulin sensitivity and PAI-1 activity (Table 4, Fig. 4)}

Significant, inverse, correlations were seen between the

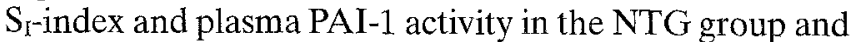
in the HTG sub-group with normal $\gamma$-GT levels. Once again there was no significant difference between the slopes of the regression lines for these relationships (Fig. 4). In contrast, no correlation was seen between the $\mathrm{S}_{\mathrm{r}}$-index and PAI-1 activity in the HTG sub-group with elevated $\gamma$-GT levels.

\section{Multivariate analysis (Table 5)}

In the multivariate analysis, parameters being significantly related to plasma PAI-1 activity in the univariate analysis were entered stepwise forward in the model.

In the NTG group, BMI and VLDL-triglycerides, were shown to significantly and independently correlate with plasma PAI-1 activity level. These two parameters explained around $50 \%$ of the variation in PAI- 1 level among NTG men.

In the HTG group, as a whole, VLDL-triglycerides, $\gamma$ GT and WH ratio were found to significantly and independently relate to plasma PAI-1 activity, together explaining about $50 \%$ of the variation in PAI- 1 level. 
Table 4. Pearson linear correlation coefficients between plasma plasminogen activator inhibitor-1 (PAI-1) activity and ${ }^{10}$ log very low density lipoprotein (VLDL) triglycerides (TG) in serum, glucose/insulin response during the oral glucose tolerance test and insulin sensitivity index $\left(\mathrm{S}_{\mathrm{I}}\right)$ in normo-(NTG) and hypertriglyceridaemic (HTG) subjects

\begin{tabular}{|c|c|c|c|c|c|c|c|}
\hline & $\begin{array}{l}\text { PAI-1 } \\
\text { vs } \\
{ }^{10} \log \text { VLDL-TG }\end{array}$ & $\begin{array}{l}\text { PAI-1 } \\
\text { vs } \\
\text { glucose } 0 \mathrm{~min}\end{array}$ & $\begin{array}{l}\text { PAI-1 } \\
\text { vs } \\
\text { glucose } 120 \mathrm{~min}\end{array}$ & $\begin{array}{l}\text { PAI-1 } \\
\text { vs } \\
\text { insulin } 0 \mathrm{~min}\end{array}$ & $\begin{array}{l}\text { PAI-1 } \\
\text { vs } \\
\text { insulin } 60 \mathrm{~min}\end{array}$ & $\begin{array}{l}\text { PAI-1 } \\
\text { vs } \\
\text { insulin } 120 \mathrm{~min}\end{array}$ & $\begin{array}{l}\text { PAI-1 } \\
\text { vs } \\
\text { S }_{1} \text {-index }\end{array}$ \\
\hline $\begin{array}{l}\text { NTG } \\
n=61\end{array}$ & $0.60^{\mathrm{b}}$ & $0.05^{\mathrm{d}}$ & $0.24^{\mathrm{d}}$ & $0.28^{d}$ & $0.30^{\mathrm{d}}$ & $0.42^{\mathrm{a}, \mathrm{d}}$ & $-0.44^{\mathrm{b}, \mathrm{d}}$ \\
\hline $\begin{array}{l}\text { HTG, } \\
\text { all } \\
n=65\end{array}$ & $0.38^{\mathrm{a}}$ & $0.43^{b}$ & 0.22 & $0.21^{\mathrm{e}}$ & 0.25 & 0.27 & $-0.35^{\mathrm{a}, \mathrm{f}}$ \\
\hline $\begin{array}{l}\text { HTG, } \\
\text { elevated } \gamma-\mathrm{GT}^{\mathrm{a}} \\
n=29\end{array}$ & 0.42 & 0.28 & 0.14 & 0.03 & 0.09 & 0.22 & $-0.04^{\mathrm{h}}$ \\
\hline
\end{tabular}

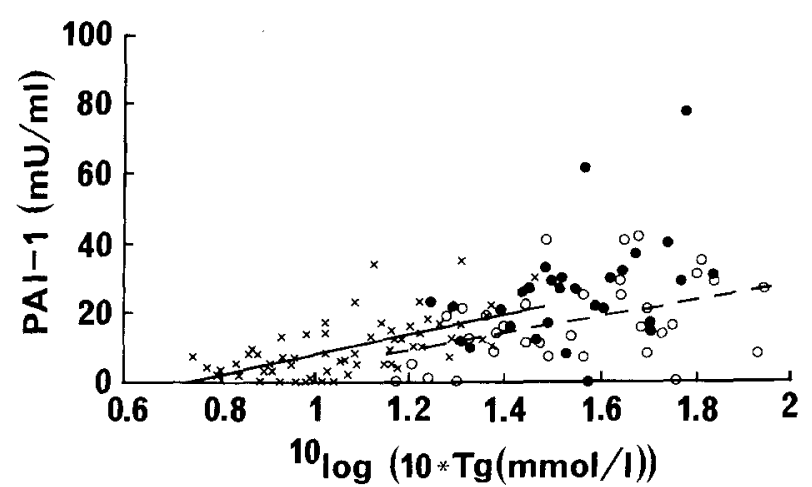

Fig. 3. Relationship between PAI-1 activity and VLDL triglycerides $x \rightarrow \times$ NTG men (equation $y=17.6 x-5.0$ ). ०--o HTG men with $\gamma$ GT $<1$ (equation $y=20.9 x-12$ ). $\bullet$ HTG men with $\gamma-\mathrm{GT} \geq 1$

When the two sub-groups of HTG men, with normal and elevated $\gamma$-GT levels, respectively, were analysed separately, VLDL-triglycerides disappeared from the final model. However, the VLDL-triglyceride relation in the HTG sub-group with elevated $\gamma$-GT levels was just below the limit of statistical significance $(p=0.05)$. In this group only $\gamma$-GT itself emerged as significant, explaining about $25 \%$ of the variation in PAI- 1 level. In contrast in the HTG sub-group with normal $\gamma$-GT levels BMI and fasting blood glucose were found to independently correlate with plasma PAI-1 activity, together explaining $65 \%$ of the variation in PAI-1 level.

Neither insulin levels - fasting or post-load - nor the $S_{\text {I }}$ index appeared as significant contributors to PAI- 1 activity in these models.

\section{Discussion}

This study, aimed at addressing the issue of whether triglycerides or insulin is the parameter most closely associated with plasma PAI-1 activity, comprised randomly selected HTG and NTG men. The results have illustrated that it is necessary to carefully define the group of subjects investi-

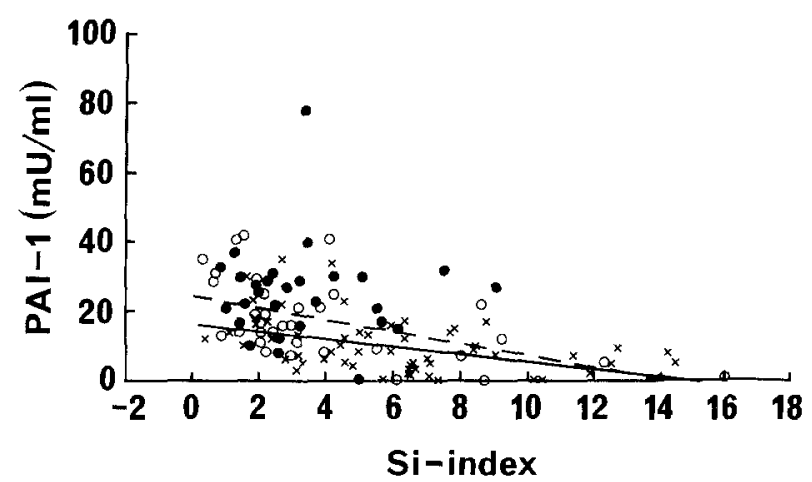

Fig. 4. Relationship between PAI-1 activity and Si-index. $x \longrightarrow x$ NTG men (equation $y=-1.07 x+16$ ). $0-\cdots \circ$ HTG men with $\gamma$-GT $<1$ (equation $y=-1.75 x+24$ ). $\bullet$ HTG men with $\gamma-\mathrm{GT} \geq 1$

gated, since, the parameter/parameters which correlated most closely to the plasma PAI-1 activity differed between NTG and HTG subjects, and, moreover, between subgroups of HTG individuals.

The NTG and HTG groups differed in several other respects, HTG men being more obese, consuming more alcohol and comprising a majority of the smokers and individuals with a sedentary life style during leisure time.

Obesity has been coupled to hypofibrinolysis in the past [25-28]. In studies where both BMI and WH ratio have been considered [17,29], BMI in non-obese and WH ratio in obese subjects have been shown to be the factor most closely linked to plasma PAI-1 levels. This is in agreement with the findings in our study since, in the multivariate analysis, BMI in the non-obese NTG group and $\mathrm{WH}$ ratio in the HTG group, respectively, was the body fat parameter best related to the plasma PAI-1 activity level. It is reasonable to assume that BMI in the NTG group and WH ratio in the HTG group reflect intraabdominal fat. This metabolically active depot mobilizes non-esterified fatty acids (NEFA) into the portal circulation [30]. If this NEFA exposure stimulates the PAI-1 secretion from hepatocytes is not known, but weight reduction, known to primarily reduce intraabdominal fat depots 
Table 5. Variables independently correlated with plasminogen activator inhibitor-1 (PAI-1) activity in plasma, by multiple linear regression analysis (stepwise forward method) in normo-(NTG) and hypertriglyceridaemic (HTG) subjects

\begin{tabular}{|c|c|c|c|c|c|c|c|}
\hline & $\begin{array}{l}\mathrm{BMI} \\
\mathrm{b}(\mathrm{SEb}) p\end{array}$ & $\begin{array}{l}\text { WH } \\
\mathrm{b}(\mathrm{SEb}) p\end{array}$ & $\begin{array}{l}{ }^{10} \log \text { VLDL-TG } \\
\mathrm{b}(\mathrm{SEb}) p\end{array}$ & $\begin{array}{l}\gamma \text {-GT } \\
\mathrm{b}(\mathrm{SEb}) p\end{array}$ & $\begin{array}{l}\text { Glucose, fasting } \\
\mathrm{b}(\mathrm{SEb}) p\end{array}$ & Multiple $R$ & $p$ \\
\hline $\begin{array}{l}\text { NTG, } \\
n=61\end{array}$ & $\begin{array}{l}1.42(0.34) \\
<0.001\end{array}$ & & $\begin{array}{l}9.05(3.42) \\
<0.05\end{array}$ & & & 0.71 & $<0.0000$ \\
\hline $\begin{array}{l}\text { HTG, } \\
\text { all } \\
n=61\end{array}$ & & $\begin{array}{l}59.58(25.02) \\
<0.05\end{array}$ & $\begin{array}{l}20.00(6.38) \\
<0.01\end{array}$ & $\begin{array}{l}5.46(1.29) \\
<0.001\end{array}$ & & 0.68 & $<0.0000$ \\
\hline $\begin{array}{l}\text { HTG, } \\
\text { elevated } \gamma \text { GT }^{\mathrm{a}} \\
n=29\end{array}$ & & & & $\begin{array}{l}6.39(2.26) \\
<0.01\end{array}$ & & 0.48 & $<0.01$ \\
\hline
\end{tabular}

$p$, Degree of significance of $\mathrm{b}$, respectively $R, \mathrm{~b}$, multiple regression coefficient; $\mathrm{SEb}$, standard error of $\mathrm{b}$.

WH, Waist to hip ratio

VLDL-TG, very low density lipoprotein triglycerides in serum; $\gamma$-GT, gammaglutamyltranspeptidase.

${ }^{2}$ Normal $\gamma$-GT $<1.00 \mu \mathrm{kat} / \mathrm{l}$; elevated $\gamma-\mathrm{GT} \geq 1.00 \mu \mathrm{kat} / \mathrm{l}$

at least in males, has repeatedly resulted in a reduction of plasma PAI-1 activity levels [31-33].

In epidemiological studies alcohol consumption has been positively associated with fibrinolytic capacity [34]. By contrast, experimental studies have shown decreased fibrinolysis after alcohol intake [34]. One possible explanation for this discrepancy may be that the pattern of alcohol consumption, e. g. daily moderate intake as opposed to binge drinking, seems to influence PAI-1 activity differently. Regular daily alcohol consumption has been shown to be followed by increased plasma PAI-1 activity [35] while binge drinking appeared to have no effect on PAI-1 levels $[34,35]$.

In our study, there were no correlations between reported alcohol consumption and PAI-1 activity, in either the NTG or in the HTG group. However, in the HTG group, serum $\gamma-\mathrm{GT}$ activity correlated significantly with plasma PAI-1 activity in both the univariate and multivariate analysis. This relationship was confined to the HTG sub-group with elevated $\gamma$-GT levels. This suggests that only if alcohol consumption is accompanied by an induction/elevation of the $\gamma$-GT enzyme activity the fibrinolytic capacity is decreased. It is known that when $\gamma$-GT elevation is connected with alcohol consumption, a daily and regular intake is present. The finding in our study of significantly higher plasma PAI-1 levels in the HTG sub-group with elevated $\gamma$-GT levels may relate to their elevated $\gamma$ GT activity, rather than to a high alcohol intake per se.

Other life-style characteristics such as smoking and degree of physical activity did not seem to confound the results in our study, since no relationships were found between these factors and plasma PAI-1 in either the NTG or in the HTG group.

Positive correlation between plasma PAI-1 and serum triglyceride levels have been demonstrated in several earlier studies $[6,12-14,36-40]$. However, there are also a number of publications reporting on absence of this relationship $[17,41-44]$. In our study, comprising randomly selected men, with and without hypertriglyceridaemia, we found significant and independent correlations between plasma PAI-1 activity and serum triglyceride concentration in the NTG group as well as in the entire HTG group.

It has been debated whether triglycerides (VLDL) or insulin is the major determinant of plasma PAI-1 activity in physiological and pathophysiological conditions. Insulin has been proposed to influence plasma PAI-1 activity either directly through stimulation of PAI-1 from hepatocytes, or indirectly through its effects on triglycerides/VLDL. The HTG group in our study, had higher glucose and insulin levels both in the fasting state and after an oral glucose load as well as lower mean $S_{I}$ index than the NTG group. Interestingly, significant correlations between plasma PAI-1 activity and fasting glucose/fasting insulin levels were found only in the HTG group. Furthermore, these relationships were confined to the HTG subgroup with normal $\gamma$-GT levels. Notably, in this group, fasting glucose rather than insulin or $\mathrm{S}_{\mathrm{I}}$ index appeared to be the parameter most closely related to plasma PAI-1 activity in the multivariate analysis.

It could be that fasting glucose levels reflect portal insulin concentrations more accurately than do systemic serum insulin levels. High portal insulin concentrations in the HTG sub-group without $\gamma$-GT elevations would then stimulate PAI-1 secretion from hepatocytes. This hypothesis is supported by the fact that patients with insulindependent diabetes, with extremely low portal insulin levels have low or subnormal PAI-1 levels. Conversely patient with non-insulin-dependent diabetes exhibit portal and systemic hyperinsulinaemia along with elevated plasma PAI-1 activity [45]. Hyperinsulinaemic clamp studies have failed to raise plasma PAI-1 levels [46] whereas the insulin augmentation by an oral glucose load, which should include portal insulin, has been shown to be followed by plasma PAI-1 elevation $[47,48]$.

Some caution in the interpretation of the relationships between insulin, insulin sensitivity and PAI-1 is necessary as the standard insulin RIA seems to measure both intact and split proinsulin [49] and since PAI-1 was related only to split insulin in one study of patients with maturity-onset diabetes [50]. Elevated concentrations of proinsulin-like 
molecules might have contributed to the basal hyperinsulinaemia and the hyperinsulinaemic responses to glucose challenge observed in the hypertriglyceridaemic men in this study.

In conclusion, our study suggests that, in the normotriglyceridaemic range, among non-obese men, serum triglyceride (VLDL) concentration substantially contributes to the variation in plasma PAI-1 activity, possibly due to a direct effect of VLDL on PAI-1 secretion [51], in addition to the degree of obesity/accumulation of intraabdominal fat. In the hypertriglyceridaemic range, however, fasting serum glucose levels - possibly reflecting portal insulin stimulation of PAI-1 secretion from the liver - significantly influence the variation in plasma PAI-1 activity level. Why, among HTG subjects with elevated $\gamma$-GT levels, the degree of activity of this enzyme itself appeared to correlate with plasma PAI-1 activity levels to a significantly higher degree than serum triglyceride (VLDL) levels or serum glucose/insulin levels, despite glucose and insulin levels comparable to those observed in the HTG sub-group with normal $\gamma$-GT activity, is currently not known.

Acknowledgements. This work was supported by grants from the Swedish Medical Research Council (19X-204, 8691), Stiftelsen Prof. N.Svartz fund and Stiftelsen för Gamla Tjänarinnor.

\section{References}

1. Assman G, Gotto AM Jr, Paoletti R (1991) The hypertriglyceridemias: risk and management. Am J Cardiol 68: $1 \mathrm{~A}-42 \mathrm{~A}$

2. Austin MA (1991) Plasma triglyceride and coronary heart disease. Arteriosclerosis Thromb 11:2-14

3. Hamsten A (1990) Hypertriglyceridaemia, triglyceride-rich lipoproteins and coronary heart disease. Baillere's Clinical Endocrinol 4: 895-922

4. Reaven GM (1988) Banting lecture 1988: role of insulin resistance in human disease. Diabetes 37: 1595-1607

5. Modan M, Halkin H, Lusky A, Segal P, Fuchs Z, Chetrit A (1988) Hyperinsulinemia is characterized by jointly disturbed plasma VLDL, LDL and HDL levels. A population-based study. Arteriosclerosis $8: 227-236$

6. Hamsten A, Wiman B, de Faire U, Blombäck M (1985) Increased plasma levels of a rapid inhibitor of tissue plasminogen activator in young survivors of myocardial infarction. N Engl $J$ Med 313: 1557-1563

7. Juhan-Vague I, Alessi MC, Joly P et al. (1986) Plasma plasminogen activator inhibitor- 1 in angina pectoris. Influence of plasma insulin and acute-phase response. Arteriosclerosis 9: 362-367

8. Juhan-Vague I, Alessi MC, Vague P (1991) Increased plasma plasminogen activator inhibitor 1 levels. A possible link between insulin resistance and atherothrombosis. Diabetologia 34: 457 . 462

9. Wiman B, Hamsten A (1990) The fibrinolytic enzyme system and its role in the etiology of thromboembolic disease. Semin Thromb Hemostas 16: 207-216

10. Nilsson TK, Johnson O (1987) The extrinsic fibrinolytic system in survivors of myocardial infarction. Thromb Res 48: 621-630

11. Wiman B, Hamsten A (1991) Impaired fibrinolysis and risk of thromboembolism. Prog Cardiovasc Dis 3: 179-192

12. Hamsten A, de Faire U, Walldius G et al. (1987) Plasminogen activator inhibitor in plasma: risk factor for recurrent myocardial infarction. Lancet II: 3-9

13. Mehta J, Mehta P, Lawson D, Goldeen T (1987) Plasma tissue plasminogen activator inhibitor levels in coronary artery disease: correlation with age and serum triglyceride concentrations. J Am Coll Cardiol 9: 263-268

14. Juhan-Vague I, Vague P, Alessi MC et al. (1987) Relationship between plasma insulin, triglyceride, body mass index, and plasminogen activator inhibitor. 1. Diabetes Metab 13:331-336

15. Vague P, Juhan-Vague I, Alessi MC, Bacher C, Valadier J (1987) Metformin decreases the high plasminogen activator inhibition capacity, plasma insulin and triglyceride levels in non-diabetic obese subjects. Thromb Haemostas 57: 326-328

16. Alessi MC, Juhan-Vague I, Kooistra T, Declerck PJ, Collen D (1988) Insulin stimulates the synthesis of plasminogen activator inhibitor 1 by hepatocellular cell line Hep G2. Thromb Haemostas 60: 491-494

17. Landin K, Stigendal L, Eriksson Eetal.(1990) Abdominal obesity is associated with an impaired fibrinolytic activity and elevated plasminogen activator inhibitor-1. Metabolism 39:1044-1048

18. Bergman RN, Beard JC, Chen M (1986) The minimal modelling method: assessment of insulin sensitivity and B-cell function in vivo. In: Clarke WL, Larner J, Pohl SL (eds) Methods in diabetes research. Wiley, New York, pp 15-34

19. The Swedish National Food Administration (1986) Food composition tables. Liber Tryck, Stockholm

20. Carlson LA (1982) Fish eye disease: a new familial condition with massive corneal opacities and dyslipoproteinaemia. Eur J Clin Invest 12: 41-53

21. Chmielewska J, Rånby M, Wiman B (1983) Evidence for a rapid inhibitor to tissue plasminogen activator in plasma. Thromb Res 31: 427-436

22. World Health Organization (1985) Diabetes mellitus. Report of WHO study group. World Health Organization technical report series 727 , Geneva

23. Welch S, Gebhart SP, Bergman RN, Phillips LS (1990) Minimal model analysis of intravenous glucose tolerance test - derived insulin sensitivity in diabetic subjects. J Clin Endocrinol Metab 71: $1508-1518$

24. Pacini G, Bergman RN (1986) MINMOD: a computer program to calculate insulin sensitivity and pancreatic responsivity from the frequently sampled intravenous glucose tolerance test. Comp Meth Prog Biomed 23: 113-122

25. Shaw DA, McNaughton D (1963) Relationship between blood fibrinolytic activity and body fatness. Lancet I: 352-354

26. Ogston DM, Andrew GM (1964) Fibrinolysis in obesity. Lancet II: $1205-1207$

27. Grace CS, Goldrick RB (1968) Fibrinolysis and body build. Interrelationship between blood fibrinolysis, body composition, and parameters of lipid and carbohydrate metabolism. J Atherosclerosis Res 8: 705-719

28. Almer LO, Janzon L (1975) Low vascular fibrinolytic activity in obesity. Thromb Res 6:171-175

29. Sundell IB, Nilsson TK, Rånby M, Hallmans G, Hellsten G (1989) Fibrinolytic variables are related to age, sex, blood pressure, and body build measurements: a cross-sectional study in Norsjö, Sweden. J Clin Epidemiol 42: 719-723

30. Björntorp P (1990) "Portal" adipose tissue as a generator of risk factors for cardiovascular disease and diabetes. Arteriosclerosis 10: $493-496$

31. Sundell IB; Dahlgren S, Rånby M, Lundin E, Stenling R, Nilsson TK (1989) Reduction of elevated plasminogen activator inhibitor levels during modest weight loss. Fibrinolysis $3: 51-53$

32. Mehrabian M, Peter JB, Barnard RJ, Lusis AJ (1990) Dietary regulation of fibrinolytic factors. Atherosclerosis $84: 25-32$

33. Huisveld IA, Leenen R, vander Kooy K et al. (1990) Body composition and weight reduction in relation to antigen and activity of plasminogen activator inhibitor (PAI-1) in overweight individuals. Fibrinolysis 4: 84-85

34. Veenstra J, te Wierik F, Kluft C (1990) Alcohol and fibrinolysis. Fibrinolysis 4 [Suppl 2]: 64-68

35. Kluft C, Veenstra J, Schaafsma G, Pikaar NA (1990) Regular moderate wine consumption for five weeks increases plasma activity of the plasminogen activator inhibitor-1 (PAI-1) in healthy young volunteers. Fibrinolysis 4 [Suppl 2]: 69-70 
36. Landin K, Tengborn L, Smith U (1990) Elevated fibrinogen and plasminogen activator inhibitor (PAI-1) in hypertension are related to metabolic risk factors for cardiovascular disease. J Int Med Res 227: 273-278

37. Sundell IB, Nilsson TK, Hallmans G, Nygren C (1988) The effect on body build, diet and endocrine factor on the extrinsic fibrinolytic system in healthy young women. Scand J Clin Lab Invest 48: $557-564$

38. Sundell IB; Nilsson TK, Hallmans G, Hellsten G, Dahlen GH (1988) Interrelationship between plasma levels of plasminogen activator inhibitor, tissue plasminogen activator, lipoprotein(a), and established cardiovascular risk factors in a north Swedish population. Atherosclerosis 80: 9-16

39. Juhan-Vague I, Valadier J, Alessi MC et al. (1987) Deficient t-PA release and elevated PA inhibitor levels in patients with spontaneous or recurrent deep venous thrombosis. Thromb Haemost $57: 67-72$

40. Juhan-Vague I, Alessi MC, Fossat C, Valadier J, Aillaud MF, Serradimigni A (1988) Clinical relevance of high PAI-1 level in patients with idiopathic-recurrent deep venous thrombosis. Fibrinolysis 2 [Supp1 2]: 85-88

41. Juhan-Vague I, Roul C, Alessi MC, Ardissone JP, Heim M, Vague $P(1989)$ Increased plasminogen activator inhibitor activity in non insulin dependent diabetic patients. Relationship with plasma insulin. Thromb Haemostas 61:370-373

42. Francis RB, Kawanishi D, Baruch T, Mahrer P, Rahimtoola S, Feinstein DI (1988) Impaired fibrinolysis in coronary artery disease. Am Heart J 115: 776-780

43. Vague P, Juhan-Vague I, Aillaud MF et al. (1986) Correlation between fibrinolytic activity, plasminogen activator inhibitor level, plasma insulin level and relative body weight in normal and obese subjects. Metabolism 35: 250-253

44. Grant MB, Fitzgerald C, Guay C, Lottenberg R (1989) Fibrinolytic capacity following stimulation with desmopressin acetate in patients with diabetes mellitus. Metabolism 38: 901-907
45. Auwerx J, Bouillon R, Collen D, Geboers I (1988) Tissue-type plasminogen activator antigen and plasminogen activator inhibitor in diabetes mellitus. Arteriosclerosis 8: 68-72

46. Juhan-Vague I, Vague P (1991) Hypofibrinolysis and insulin-resistance. Diabetes Metab 17:96-100

47. Medvescek M, Keber D, Stegnar M, Borovnicar A (1990) Plasminogen activator inhibitor 1 response to a carbohydrate meal in obese subjects. Fibrinolysis 4: 89-90

48. Keber D, Borovnicar A (1989) Difference in insulin and plasminogen activator inhibitor 1 (PAI-1) response after high carbohydrate as opposed to high fat meal. Thromb Haemost 62: 291

49. Temple RC, Carrington CA, Luzio SD et al. (1989) High specific insulin assay reveals uniform insulin deficiency in non-insulindependent diabetes. Lancet I: 293-295

50. Nagi DK, Hendra TJ, Ryle AJ et al. (1990) The relationships of concentrations of insulin, intact proinsulin and 32-33 split proinsulin with cardiovascular risk factors in type 2 (non-insulin-dependent) diabetic subjects. Diabetologia 33: 532-537

51. Stiko-Rahm A, Wiman B, Hamsten A, Nilsson J (1990) Secretion of plasminogen activator inhibitor- 1 from cultured human umbilical vein endothelial cells is induced by very low density lipoprotein. Arteriosclerosis 10: 1067-1073

Received: 1 September 1992

and in revised form: 24 March 1993

Dr. A. Asplund-Carlson

King Gustav V Research Institute

Karolinska Hospital

Box 60004

S-10401 Stockholm

Sweden 